\title{
Рекомендации 2016 Европейского общества кардиологов по диагностике и лечению острой и хронической сердечной недостаточности (избранные положения)*
}

Сердечная недостаточность (CH) - это клинический синАром, характеризующийся ряАом типичных симптомов (например, одышка, отек голеней, повышенная утомляемость), которые могут сопровожАаться объективными признаками (например, повышенное Аавление в яремной вене, влажные хрипы в легких, периферические отеки) вслеАствие структурной и/или функциональной патологии серАца, привоАящей к уменьшению серАечного выброса и/или повышению внутрисерАечного Аавления в покое или при стрессе (табл. 1).

\section{Симптомы и объективные признаки}

Симптомы зачастую неспецифичны, поэтому не помогают в Аифференцировании СН от Аругих состояний (табл. 2).

Таблица 1. Определение сердечной недостаточности при сохранной (HFpEF), умеренно сниженной (HFmrEF) и сниженной фракции выброса (HFrEF)

\begin{tabular}{|c|c|c|c|c|}
\hline \multicolumn{2}{|c|}{ Tип CH } & HFrEF & HFmrEF & HFpEF \\
\hline \multirow[b]{3}{*}{ Критерии } & 1 & Симптомы \pm признаки * & Симптомы \pm признаки * & Симптомы \pm признаки * \\
\hline & 2 & ФВЛЖ $<40 \%$ & ФВЛЖ 40-49\% & ФВлЖ $\geq 50 \%$ \\
\hline & 3 & - & $\begin{array}{l}\text { 1. Повышенные уровни натрийуретических пептидов * * } \\
\text { 2. Хотя бы один из дополнительных критериев: } \\
\text { - органическая патология сердца } \\
\text { (ГЛЖ и/или ДЛП); } \\
\text { - диастолическая дисфункция }\end{array}$ & $\begin{array}{l}\text { Повышенные уровни натрийуретических пептидов * * } \\
\text { Хотя бы один из дополнительных критериев: } \\
\text { - органическая патология сердца (ГЛЖ и/или ДЛП); } \\
\text { - диастолическая дисфункция }\end{array}$ \\
\hline
\end{tabular}

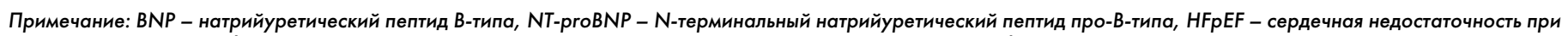

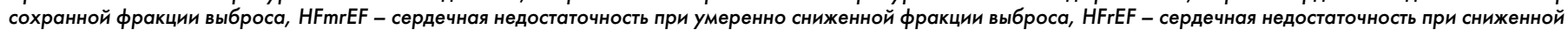

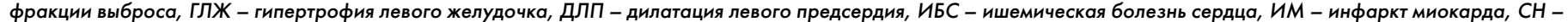

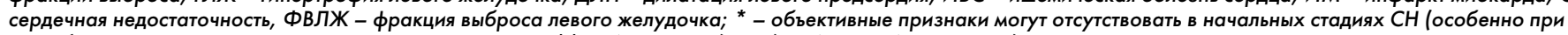
HFpEF), а также у пациентов, принимающих диуретики; ** - BNP >35 пг/мл и/или NT-proBNP>125 пг/мл.

Таблица 2. Типичные симптомы и объективные признаки сердечной недостаточности

\begin{tabular}{|c|c|}
\hline Симптомы & Объективные признаки \\
\hline Типичные & Специфические \\
\hline $\begin{array}{l}\text { - Одышка } \\
\text { - Ортопноэ } \\
\text { - Пароксизмальная ночная одышка } \\
\text { - Снижена толерантность к физической нагрузке } \\
\text { - Повышенная утомляемость, дольше происходит восстановление } \\
\text { после физической нагрузки } \\
\text { - Отек голеней }\end{array}$ & $\begin{array}{l}\text { - Повышение давления в яремной вене } \\
\text { - Гепатоюгулярный рефлюкс } \\
\text { - Третий тон сердца (ритм галопа) } \\
\text { - Латеральное смещение верхушечного толчка }\end{array}$ \\
\hline Менее типичные & Менее специфические \\
\hline $\begin{array}{l}\text { - Ночной кашель } \\
\text { - Свистящее дыхание, дистанционные хрипы } \\
\text { - Ощущение вздутия } \\
\text { - Потеря аппетита } \\
\text { - Спутанность сознания (особенно у пожилых лиц) } \\
\text { - Депрессия } \\
\text { - Ощущение сердцебиения } \\
\text { - Головокружение } \\
\text { - Обморок } \\
\text { - Бендопноэ (появление одышки при наклоне вперед) [7] }\end{array}$ & $\begin{array}{l}\text { - Увеличение массы тела (>2 кг в неделю) } \\
\text { - Потеря массы тела (при запущенной СН) } \\
\text { - Кахексия } \\
\text { - Аускультативные шумы в сердце } \\
\text { - Периферические отеки (голени, поясница, мошонка) } \\
\text { - Крепитация в легких при аускультации } \\
\text { - Снижение вентиляции и тупой перкуторный звук над основаниями легких } \\
\text { (плевральный выпот) } \\
\text { - Тахикардия } \\
\text { - Нерегулярный пульс } \\
\text { - Тахипноэ } \\
\text { - Дыхание Чейна-Стокса } \\
\text { - Гепатомегалия } \\
\text { - Асцит } \\
\text { - Холодные конечности } \\
\text { - Олигурия } \\
\text { - Низкое пульсовое давление }\end{array}$ \\
\hline
\end{tabular}

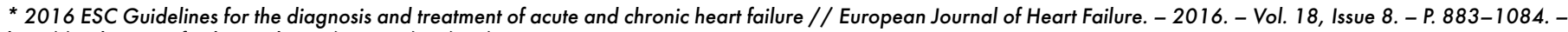
http://eurhearti.oxfordjournals.org/content/37/27/2129. 
Симптомы и объективные признаки СН в результате залержки жиАкости в организме могут быстро разрешаться при приеме Аиуретиков. Такие объективные признаки, как повышение Аав^ения в яремной вене и смещение верхушечного толчка, могут быть более специфичными, но их тяжелее выявить, и воспроизводимость невысока [1-3]. Выявить симптомы и объективные признаки может оказаться особенно труАно у лиц с ожирением, с хроническим заболеванием легких и у пожилых пациентов [4-6]. У молодых пациентов с СН по сравнению с пожилыми зачастую отличаются этиология, клиническая картина и исходы заболевания.

Алгоритм Аиагностики СН при постепенном развитии состояния показан на рисунке 1.

\section{Медикаментозная терапия сердечной недостаточности с пониженной фракцией выброса}

\section{Цели лечения СерАечной неАОстаточности}

Основные залачи лечения пациентов С CH - улучшить клиническое состояние, функционирование и качество жизни, преАотвратить необхоАимость стационарного лечения и снизить смертность. Тот факт, что некоторые меАикаменты А^я лечения СН оказывают негативное влияние на Аолгосрочные исходы, несмотря на хорошую эффективность по краткосрочным суррогатным маркерам, застави^ обратить взгляАЫ РУковоАящих органов и созАателей кАинических руководств на Аанные о заболеваемости и смертности с целью поиска и УтвержАения новых метоАов/среАств А^я ^ечения СН. ПреАотвращение госпитализаций (необхоАимости стационарного лечения) и улучшение функциональных возможностей пациента яв^яются важными факторами в аспекте контроля уровня смертности [8-10].

Терапевтические стратегии по применению меАикаментов/устройств пациентам с СерАечной неАОстаточностью при сниженной фракции выброса (HFrEF) и рекоменАации по кажАОму из вариантов суммированы на рисунке 2.

Нейрогормональные антагонисты (ингибиторы ангиотензинпревращающего фермента - ИАПФ, антагонисты минералокортикоиАных рецепторов АМР и блокаторы $\beta$-алренорецепторов - $\beta$-алреноблокаторы) способны улучшить выживаемость пациентов с HFrEF и рекоменАованы Аля лечения всехпациентов с HFrEF при условии хорошей переносимости и отсутствии противопоказаний. Новое соединение (LCZ696), ность. комбинирующее в своей структуре участки молекул блокаторов ангиотензиновых рецепторов - БАР (валсартан) и ингибитор рецептора неприлизина (сакубитрил), показало превосхоАСтво наА ИАПФ (эналапри^) в Снижении риска смерти или Госпитализации по причине СН в ОАНОМ КАиничеСКОМ ИССАеАОвании со строгими критериями вкАючения/искАючения [11]. Тем не менее, сочетание сакубитрил/валсартан рекоменловано А^я замены ИАПФ при амбулаторном ^ечении пациентов с HFrEF И отсутствием позитивной Аинамики, несмотря на оптимальную терапию, и при соответствии критериям этого исслеАования. Нет окончательной уверенности в том, что БАР снижают смертность пациентов с HFrEF, и применение БАР АОАжно быть ограничено ^ишь А^я пациентов, не переносящих ИАПФ Аибо принимающих ИАПФ, но не переносящих АМР. ИвабраАин снижает повышенную частоту сокращений серАца (ЧСС), часто наблюАаемую при HFrEF, и способен улучшать клинические исходы, поэтому его назначение рассматривается в соответствующих ситуациях.

\section{Антагонисты рецепторов минералокортикоиАов/ альАостерона}

AMP (спиронолактон и эплеренон) блокируют рецепторы, связывающие альдостерон и с различной степенью афинно-

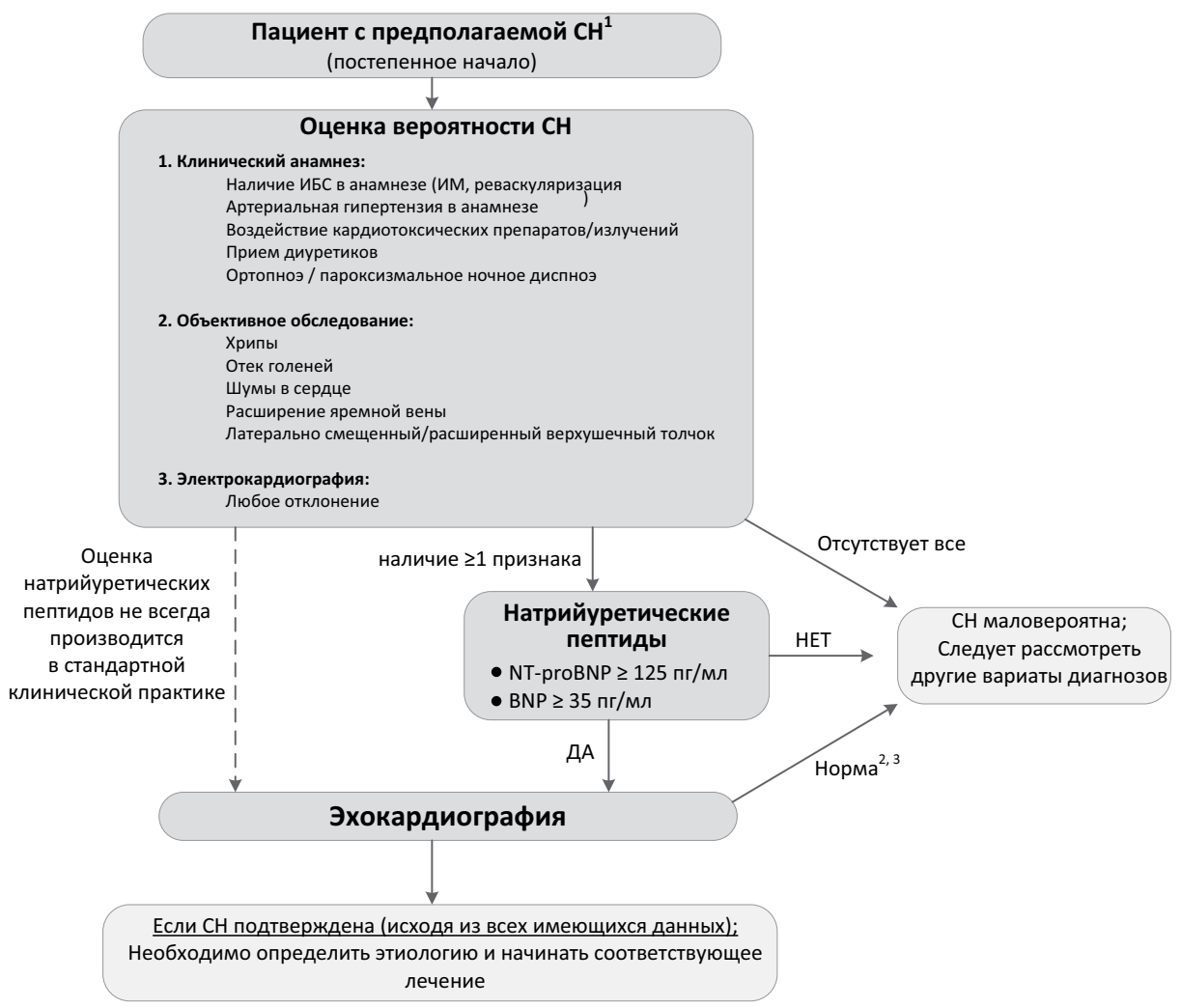

Примечание: BNP - натрийуретический пептид B-типа; NT-рroBNP - N-терминальный натрийуретический пептид про-В-типа, ИБС - ишемическая болезнь сердца, ИМ - инфаркт миокарда, СН - сердечная недостаточ-

'У пациента симптомы, типичные для СН (см. табл. 2).

${ }^{2}$ Нормальные показатели объёма и функции предсердий и желудочков.

${ }^{3}$ Рассмотрите другие причины повышения натрийуретических пептидов.

Рис. 1. Алгоритм диагностики сердечной недостаточности при постепенном развитии состояния 
Таблица 3. Практические рекомендации по применению антагонистов минералокортикоидных рецепторов пациентам с сердечной недостаточностью и сниженной фракцией выброса 1

\section{Для чего?}

Для улучшения клинической картины, выживаемости и снижения риска госпитализаций пациентов по причине $\mathrm{CH}$

\section{Кому и когда?}

\section{Показания:}

Теоретически - всем пациентам с персистирующей клинической картиной (классы II-IV по NYHA) и ФВЛЖ $\leq 35 \%$, несмотря на прием ИАПФ (или БАР) и

В-адреноблокаторов

Противопоказания:

Известные аллергические / другие побочные реакции (лекарственные)

Предосторожности / необходимость врачебной консультации:

1. Выраженная гиперкалиемия $\left(\mathrm{K}^{+}>5,0 \text { ммоль/л) }\right)^{2}$.

2. Выраженная почечная недостаточность (креатинин $>221$ мкмоль/л [ $2,5 \mathrm{Mr} /$ дл] или $\mathrm{pCKФ} \mathrm{<30} \mathrm{мл/мин/1,73} \mathrm{м²)} 2$.

3. Обращать внимание на лекарственные сочетания:

- калийсодержащие препараты / калийсберегающие диуретики (например, амилорид и триамтерен; остерегаться комбинированных препаратов, имеющих в составе фуросемид);

- ИАПФ/БАР/ингибиторы ренина ${ }^{3}$;

- НПВП ${ }^{4}$

- триметоприм/триметоприм-сульфаметоксазол;

- заменители соли с высоким содержанием калия;

- мощные ингибиторы СYРЗА4, например, кетоконазол, итраконазол, нефазодон, телитромицин, кларитромицин, ритонавир, нелфинавир (при использовании эплеренона)

\section{Какой АМР выбрать и в какой дозе?}

Эплеренон: начальная доза - 25 мг один раз в сутки, целевая доза - 50 мг один раз в сутки.

Спиронолактон: начальная доза - 25 мг один раз в сутки, целевая доза - 50 мг один раз в сутки.

\section{Где?}

Амбулаторно или стационарно.

Исключения - см. «Предосторожности / необходимость врачебной консультации»

\section{Как принимать?}

1. Проверять функцию почек и уровень электролитов (особенно $\mathrm{K}+$ ).

2. Начинать с меньшей дозы (см. выше).

3. Решать вопрос о повышении дозы через 4-8 недель приема.

4. Проводить биохимический анализ крови на 1-й и 4-й неделе после начала лечения или повышения дозы, далее - на 8-й и 12-й неделе; 6-м, 9-м и 12-м месяце; затем каждые 4 месяца.

- При повышении $\mathrm{K}^{+}$более 5,5 ммоль/л или креатинина до 221 мкмоль/л (2,5 мг/дл) / рСКФ <30 мл/мин/ 1,73 м² - половина дозы и более частый контроль биохимических показателей.

- При повышении $\mathrm{K}^{+}>6,0$ ммоль/л или креатинина >310 мкмоль/л (3,5 мг/ял) / рСКФ <20 мл/мин/ 1,73 м² - немедленно прекратить прием АМР и обратиться к врачу.

5. Младший медперсонал может помочь в обучении пациентов, наблюдении (лично или по телефону), мониторинге биохимических показателей и повышении дозы

\section{Разрешение проблем}

\section{Ухудшение функции почек / гиперкалиемия:}

См. «Как принимать?».

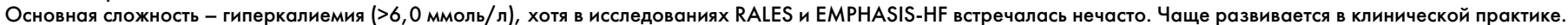

Уровень калия по верхней планке нормы может быть, наоборот, желателен у пациентов с СН, особенно на фоне приема дигоксина.

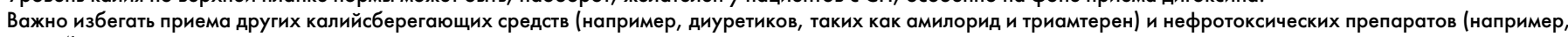
$\left.\mathrm{H} \Pi \mathrm{B} \Pi^{4}\right)$.

Риск гиперкалиемии выше в случае добавления АМР на фоне приема сочетания ИАПФ и БАР, чем при добавлении АМР на фоне приема одного из препаратов (ИАПФ или БАР). Сочетание ИАПФ + БАР + АМР НЕ РЕКОМЕНДУЕТСЯ (сМ. рекомендации ниже).

Некоторые заменители соли содержат много калия.

У мужчин, принимающих спиронолактон, изредка развивается гинекомастия (необходимо рассмотреть возможность замены препарата на эплеренон).

\section{Рекомендации пациентам}

Объяснение возможных выгод (см. «Для чего?»).

Лечение назначается с целью улучшить клиническую картину, предотвратить усугубление СН, приводящее к госпитализации, и повысить выживаемость.

Улучшение симптомов развивается в период от нескольких недель до нескольких месяцев с начала лечения.

Избегать НПВП ${ }^{4}$, не назначенных врачом (например, приобретенных безрецептурных препаратов), и заменителей соли с высоким содержанием $\mathrm{K}^{+}$

При появлении диареи/рвоты либо при развитии инфекционного заболевания с лихорадкой и обильным потоотделением пациент должен быть предупрежден об опасности обезвоживания и электролитного дисбаланса, а также о необходимости обратиться к врачу в подобных случаях

Примечание: АМР - антагонисты минералокортикоидных рецепторов, БАР - блокатор ангиотензиновых рецепторов, ИАПФ - ингибитор ангиотензинпревращающего фермента, НПВП - нестероидные противовоспалительные препараты, рСКФ - расчетная скорость клубочковой фильтрации, СН - сердечная недостаточность, ФВЛЖ - фракция выброса левого желудочка, EMPHASIS-HF - изучение частоты госпитализаций и выживаемости пациентов с сердечной недостаточностью, принимающих эплеренон (Eplerenon in Mild Patients Hospitalization and Survival Study in Heart Failure), NYHA - Нью-Йоркская ассоциация сердца (New York Hеart Association), RALES - Randomized Aldactone Evaluation Study.

'Рекомендации, приведенные в таблице 3, отражают мнение экспертов, базирующееся на соответствующих клинических исследованиях (препараты, схемы дозирования, целевые дозы, мониторинг пациентов, выгоды лечения, побочные реакции) и практическом опыте.

${ }^{2}$ Крайне важно придерживаться указанных предосторожностей и дозировок с целью избежать серьезной гиперкалиемии.

${ }^{3}$ Ингибиторы ренина не рекомендованы при СН.

${ }_{4}^{4}$ Избегать приема НПВП, кроме случаев крайней необходимости. 


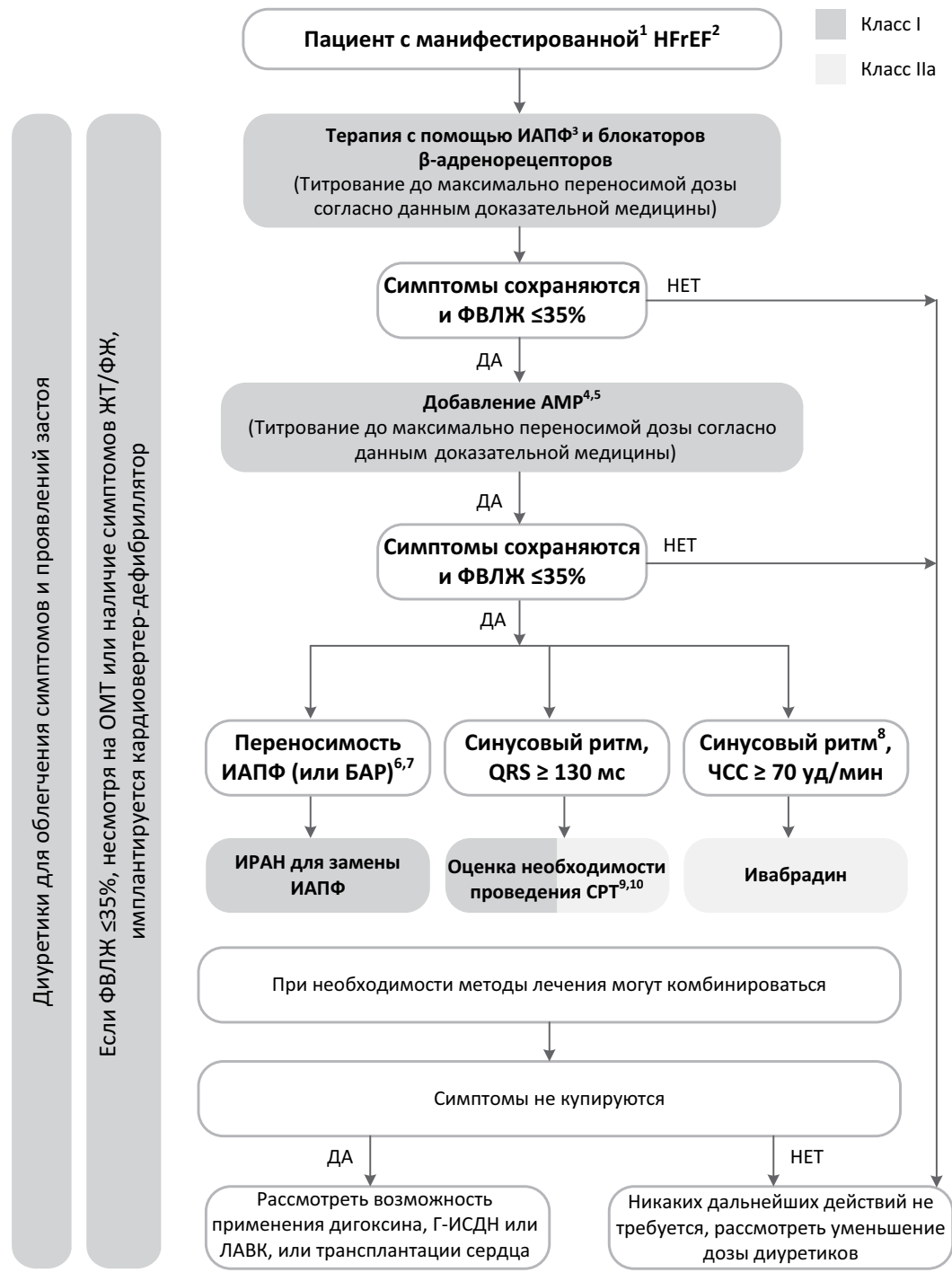

Примечание: темно-серый цвет соответствует классу I рекомендаций; серый - классу II. БАР - блокатор ангиотензиновых рецепторов, БЛНПГ - блокада левой ножки пучка Гиса, Г-ИСДН - гидралазин и изосорбита динитрат, ИАПФ - ингибитор ангиотензинпревращающего фермента, ИРАН - ингибитор рецепторов ангиотензина-неприлизина, ИБС - ишемическая болезнь сердца, ИКД - имплантируемый кардиовертер-дефибриллятор, ИМ - инфаркт миокарда, ЛАВК - левожелудочковый аппарат вспомогательного кровообращения (сердечная помпа), ОМТ - оптимальная медикаментозная терапия, $\mathrm{CH}$ - сердечная недостаточность, СРТ - сердечная ресинхронизирующая терапия, ФВЛЖ - фракция выброса левого желудочка, ФЖ - фибрилляция желудочков, ФП - фибрилляция предсердий, ЧСС - частота сердечных сокращений, BNP - натрийуретический пептид B-типа, NT-proBNP - N-терминальный натрийуретический пептид про-В-типа, HFrEF - сердечная недостаточность со сниженной фракцией выброса, NYHA - Нью-Йоркская ассоциация сердца (New York Heart Association).

'Манифестация - классы II-IV по NYHA.

${ }^{2} \mathrm{HFrEF}-$ ФВЛЖ $<40 \%$.

${ }^{3}$ Если ИАПФ не переносятся либо имеются противопоказания - используйте БАР.

${ }^{4}$ Если АМР не переносятся либо имеются противопоказания - используйте БАР.

${ }^{5}$ При наличии за последние 6 месяцев госпитализации по причине $\mathrm{CH}$ либо повышенных показателей натрийуретических пептидов (BNP >250 пг/мл или NT-proBNP >500 пг/мл у мужчин и 750 мкг/мл у женщин).

${ }^{6}$ При наличии повышения уровня натрийуретических пептидов в плазме крови (BNP $\geq 150$ пг/мл или NT-proBNP $\geq 600$ пг/мл либо при условии госпитализации за последние 12 месяцев по причине СН и показателях BNP $\geq 100$ пг/мл или NT-proBNP $\geq 400$ пг/мл).

${ }^{7}$ В дозе, эквивалентной 10 мг эналаприла 2 раза в сутки.

${ }^{8}$ При госпитализации в течение предыдущего года по причине $\mathrm{CH}$.

${ }^{9} \mathrm{CPT}$ рекомендована при QRS $\geq 130$ мс и БЛНПГ (при синусовом ритме).

${ }^{10} \mathrm{CPT}$ должна/может быть рассмотрена при QRS $\geq 130$ мс и не-БЛНПГ (при синусовом ритме) либо у пациентов с ФП при проведении экстренного бивентрикулярного захвата (решается индивидуально).

Рис. 2. Алгоритм лечения пациентов с манифестированной сердечной недостаточностью и сниженной фракцией выброса сти - Аругие стероидные гормоны (например, кортикостероиАы, андрогены). Спиронолактон или эплеренон рекоменАованы всем пациентам с клиническими проявлениями HFrEF и фракцией выброса левого желудочка (ФВАઋ) $\leq 35 \%$ (несмотря на прием ИАПФ и $\beta$-адреноблокаторов) с целью снижения смертности и частоты госпитализаций по причине $\mathrm{CH}[12,13]$.

Необходимо соблюАать осторожность при назначении AMP пациентам с нарушением функции почек и уровнем калия в сыворотке крови >5,0 ммоль/^. НеобхоАимо провоАИть СогАасно КАиническому статусу регулярные проверки уровня калия в сыворотке крови и функции почек (табл. 3).

\section{Список использованной литературы}

1. van Riet E.E.S. Prevalence of unrecognized heart failure in older persons with shortness of breath on exertion / E.E.S. van Riet, A.W. Hoes, A. Limburg et al. // Eur. J. Heart Fail. -2014. - Vol. 16. - P. 772-777.

2. Kelder J.C. The diagnostic value of physical examination and additional testing in primary care patients with suspected heart failure / J.C. Kelder, M.J. Cramer, J. van Wiingaarden et al. // Circulation. - 2011. - Vol. 124. - P. 2865-2873.

3. Boonman-de Winter L.J.M. Efficiently screening heart failure in patients with type 2 diabetes / L.J.M. Boonman-de Winter, F.H. Rutten, M.J. Cramer et al. // Eur. J. Heart Fail. - 2015. - Vol. 17. P. 187-195.

4. Rutten F.H. Recognising heart failure in elderly patients with stable chronic obstructive pulmonary disease in primary care: cross sectional diagnostic study / F.H. Rutten, K.G.M. Moons, M.-J.M. Cramer et al. // BMJ. - 2005. - Vol. 331. - P. 1379.

5. Hawkins N.M. Heart failure and chronic obstructive pulmonary disease: diagnostic piffalls and epidemiology / N.M. Hawkins, M.C. Petrie, P.S. Jhund et al. // Eur. J. Heart Fail. - 2009. Vol. 11. - P. 130-139

6. Daniels L.B. How obesity affects the cut-points for B-type natriuretic peptide in the diagnosis of acute heart failure. Results from the Breathing Not Properly Multinational Study / L.B. Daniels, P. Clopton, V. Bhalla et al. // Am. Heart J. - 2006. - Vol. 151. P. 999-1005

7. Thibodeau J.T. Characterization of a novel symptom of advanced heart failure: bendopnea / Thibodeau J.T., Turer A.T., Gualano S.K. et al. // JACC Heart Fail. - 2014. - Vol. 2. P. 24-31.

8. Stewart S. The current cost of heart failure to the National Health Service in the UK / S. Stewart, A. Jenkins, S. Buchan et al. // Eur. J. Heart Fail. - 2002. - Vol. 4 - P. 361-371.

9. Gheorghiade M. Recognizing hospitalized heart failure as an entity and developing new therapies to improve outcomes: academics', clinicians', industry's, regulators', and payers' perspectives / M. Gheorghiade, A.N. Shah, M. Vaduganathan et al. // Heart Fail. Clin. - 2013. - Vol. 9. - P. 285-290, v-vi.

10. Ambrosy A.P. The global health and economic burden of hospitalizations for heart failure / A.P. Ambrosy, G.C. Fonarow, J. Butler et al. // J. Am. Coll. Cardiol. - 2014. - Vol. 63. - P. 1123-1133.

11. McMurray J.J. PARADIGM-HF Investigators and Committees. Angiotensin-neprilysin inhibition versus enalapril in heart failure / McMurray J.J., Packer M., Desai A.S. et al. // N. Engl. J. Med. 2014. - Vol. 371. - P. 993-1004.

12. Pitt $B$. The effect of spironolactone on morbidity and mortality in patients with severe heart failure / B. Pitt, F. Zannad, W.J. Remme et al. // N. Engl. J. Med. - 1999. - Vol. 341. - P. 709-717.

13. Zannad F. Eplerenone in patients with systolic heart failure and mild symptoms / F. Zannad, J.J.V. McMurray, H. Krum et al. // N. Engl. J. Med. - 2011. - Vol. 364. - P. 11-21. 